\title{
Knowledge and Oral Health Attitudes among Care Providers of Children with Intellectual Disabilities: A Cross-sectional Study
}

\author{
${ }^{1}$ Prajakta P Shanbhag, ${ }^{2}$ Sabita M Ram, ${ }^{3}$ Bharat Gupta
}

\begin{abstract}
Background: Intellectual disability is characterized by significant limitations in both intellectual functioning and in adaptive behavior, which covers many everyday social and practical skills. This disability originates before the age of 18 years. Intellectual disability is also known as mental retardation (MR). The knowledge and awareness among parents, guardians or care providers of individuals with intellectual disabilities is extremely important since they play an important role in the formation and maintenance of oral health in their children.
\end{abstract}

Objectives: This study was carried out to gauge the awareness of care providers of intellectually disabled children from two different institutions in Mumbai and Navi Mumbai, India concerning their oral hygiene.

Materials and methods: A simple prestructured questionnaire was distributed among the care providers at two recognized institutions for children with intellectual disabilities in order to determine their knowledge and awareness as regards to the oral hygiene practices and significance of good oral health. The questionnaire was distributed among 120 parents, guardians or care providers of intellectually disabled children, out of which 103 care providers completed the questionnaire.

Results: The knowledge and awareness of parents was reasonable, but their oral health attitudes were lacking satisfaction. In spite of this, it was seen that the care providers in this study acknowledged the importance of good oral health and its implications on the general well-being of their children. The study revealed that $83 \%$ of care providers were unaware about the importance of fluoride in prevention of dental caries, although $95.10 \%$ were interested in educating themselves about the importance of oral health.

Conclusion: The parents/guardians of intellectually disabled children need to be counseled and made conscious about the consequences of negligence toward the oral health of their intellectually disabled children, and the significance of regular dental check-ups. They must be made aware of the various options available in order to prevent the occurrence of oral ailments in their children.

Keywords: Attitudes, Care providers, Intellectually disabled.

\footnotetext{
${ }^{1}$ Intern, ${ }^{2}$ Dean, ${ }^{3}$ Senior Lecturer

1,3Department of Public Health Dentistry, MGM Dental College Navi Mumbai, Maharashtra, India

${ }^{2}$ Department of Prosthodontics, MGM Dental College, Navi Mumbai, Maharashtra, India

Corresponding Author: Prajakta P Shanbhag, Intern Department of Public Health Dentistry, MGM Dental College Navi Mumbai, Maharashtra, India, Phone: 9819777576 , e-mail: prajakta.p.shanbhag@gmail.com
}

How to cite this article: Shanbhag PP, Ram SM, Gupta B. Knowledge and Oral Health Attitudes among Care Providers of Children with Intellectual Disabilities: A Cross-sectional Study. J Contemp Dent 2014;4(2):92-98.

Source of support: Nil

Conflict of interest: None

\section{INTRODUCTION}

Intellectual disability is characterized by significant limitations in both intellectual functioning and in adaptive behavior, which covers many everyday social and practical skills. This disability originates before the age of 18 years. ${ }^{1}$ Intellectual disability is also known as mental retardation (MR). It is a generalized disorder appearing before adulthood, characterized by significantly impaired cognitive functioning and deficits in two or more adaptive behaviors. Intellectual disability affects the mind, the body and the skills people use in everyday life like thinking, talking and self-care. People with disabilities often need extra help to attain and preserve good health. Oral health is no exception.

Children recognized as having an intellectual disability are a significant group in terms of oral health, somewhat because of their dependence on others for the management of self care. ${ }^{2}$ However, there can be considerable variation in the dependency according to the type and severity of the disorder. ${ }^{3}$ Children with more severe conditions and from low income families are predominantly at risk with high dental needs and poor access to care. ${ }^{4}$ The reasons consist of regular use of medications high in sugar, less clearance of food from the oral cavity, impaired salivary function, predilection for carbohydrate-rich foods and oral aversions. ${ }^{4,5}$

The oral health problems that are seen to be more prevalent in individuals with intellectual disabilities as compared to the general population are periodontal disease: Medications, malocclusion, multiple disabilities and poor oral hygiene combine to add to the risk of periodontal disease in people with intellectual disability; dental caries: individuals with intellectual disability develop caries at the same rate as the general population. The prevalence of untreated dental caries, however, is higher among people with intellectual disability, malocclusion: the occurrence of malocclusion in people with intellectual disability is comparable to that 
found in the general population, except for those with coexisting conditions, such as cerebral palsy or Down syndrome; missing permanent teeth, delayed eruption and enamel hypoplasia are more frequent in people with intellectual disability; damaging oral habits, such as bruxism, mouth breathing, tongue thrusting, self-injurious behavior, such as picking at the gingiva or biting the lips, and eating objects and substances, such as gravel, or pens are an issue for some individuals with intellectual disability. ${ }^{7}$

At a health systems level, oral health care is complicated by a lack of amalgamation between medical and dental professions as the two systems operate as separate entities. On an individual level, this lack of communication between disability services, government clinics and general practitioners results in inadequate knowledge of available dental services among caregivers and families of intellectually disabled children. Nelson, Getzin, Graham et $\mathrm{al}^{6}$ divided barriers from the parents' point of view into two categories: environmental and non-environmental. Major environmental barriers include the inability to find a dentist who would treat their child and financial considerations. Nonenvironmental barriers include the child's perceived fear of the dentist, the child's inability to cooperate for dental examinations. ${ }^{4,6} \mathrm{In}$ addition, fear and anxiety are the most common reasons for avoiding dental care.

\section{AIMS AND OBJECTIVES}

\section{Aim}

To determine knowledge and oral health attitudes among care providers of children with intellectual disabilities, by means of a cross-sectional survey.

\section{Objectives}

1. To review the oral hygiene practices carried out by care providers of intellectually disabled children to maintain the oral health of their children.

2. To determine the knowledge of care providers of intellectually disabled children concerning oral health problems and the importance of preventing them.

3. To determine the level of awareness of care providers of intellectually disabled children regarding the implications of bad oral health on the general well-being of their children.

4. To gauge the willingness of the care providers in educating themselves in order to impart better care to their children.

\section{MATERIALS AND METHODS}

A suitable and reliable close-ended questionnaire was formulated, validated and then distributed among the care providers of intellectually disabled children at two recognized institutions for children with special healthcare needs in order to determine their knowledge and awareness as regards to the oral hygiene practices of their children and significance of good oral health.

The variables included in the questionnaire were:

1. Oral hygiene practices among the intellectually disabled children.

2. Awareness of the care providers about gingival health, plaque and tooth decay.

3. Knowledge and awareness of dental and general health among the care providers of intellectually disabled children.

4. Attitude toward professional dental care.

Based on the above variables, a questionnaire was formed, which is in a simple tick-box format comprising of 14 close-ended questions have single or multiple answers.

This survey was a cross-sectional study carried out among 120 care providers of intellectually disabled children, out of which 103 care providers completed the questionnaire. The proposal, including the ethical views was approved by the Ethics Committee. The care providers of intellectually disabled children at the above said institutions were targeted at the monthly parent-teacher meeting. The questionnaires were distributed to all parents present, at the beginning of the meeting and collected at the end.

Study objectives were described to the care providers, after which the participant information statement and survey questionnaire was distributed. Informed consent was implied by the voluntary completion and return of the questionnaire at the end of the meeting. The survey was conducted on care providers of children with intellectual disabilities only, in the age range of 5 to 18 years. The care providers absent on the day of the survey distribution were not included in the study to prevent contamination of data.

\section{STATISTICAL EVALUATION}

The data obtained from the care providers of intellectually disabled children after completion of the questionnaire was compiled. Further statistical analysis was done using the chi-square test for association between attributes. The analysis was performed using the SPSS (Statistical package for Social Sciences), version 16.0. Statistical significance, i.e. p-value was set at 0.0005 .

The statistical evaluation suggested that there is no independent variable. There are several dependent variables (each question has a single dependent variable). For some dependent variables with $2 / 3$ levels, the frequencies/percentages are calculated. To check if these frequencies vary significantly from the expected (considering equal frequencies across the levels), chi-square test was used. For some 
groups of dependent variables with two levels (yes and no) multiple response analyses were carried out.

\section{RESULTS}

Oral hygiene habits among the study population: The data reveals that maximum care providers use toothbrush and toothpaste $(\sim 98 \%)$ for maintaining oral hygiene.
A very small percentage of care providers (2\%) use toothpaste/toothpowder and finger (Table 1). It was seen that maximum children brushed their teeth with toothpaste or toothpowder once daily $(\sim 74 \%)$, whereas the rest $(\sim 26 \%)$ brushed their teeth twice daily (see Table 1$)$. The study revealed that majority of care providers $(\sim 77 \%)$ assisted their children in brushing their teeth, and a

Table 1: Data regarding the knowledge and awareness of the care providers of intellectually disabled children

\begin{tabular}{|c|c|c|}
\hline Oral hygiene method used & $N$ (frequency) & $N(\%)$ \\
\hline Toothbrush and toothpaste & 101 & 98.1 \\
\hline Toothpaste/toothpowder and finger & 2 & 1.90 \\
\hline Total & 103 & 100 \\
\hline \multicolumn{3}{|l|}{ Swallowing of toothpaste } \\
\hline Yes & 29 & 28.2 \\
\hline No & 42 & 40.8 \\
\hline Sometimes & 32 & 31.1 \\
\hline Total & 103 & 100 \\
\hline \multicolumn{3}{|l|}{ Brushing intervals } \\
\hline At morning & 76 & 73.8 \\
\hline At morning and before bed & 27 & 26.2 \\
\hline Total & 103 & 100 \\
\hline \multicolumn{3}{|l|}{ Role of parent in supervision } \\
\hline Parent assist the child & 80 & 77.7 \\
\hline Parent watches and advises & 21 & 20.4 \\
\hline Parent only advises but does not watch & 2 & 1.9 \\
\hline Total & 103 & 100 \\
\hline \multicolumn{3}{|l|}{ Do sweets affect dental health? } \\
\hline Yes & 102 & 99 \\
\hline No & 1 & 1 \\
\hline Total & 103 & 100 \\
\hline \multicolumn{3}{|l|}{ Does health of mouth affect health of body? } \\
\hline Yes & 102 & 99 \\
\hline No & 1 & 1 \\
\hline Total & 103 & 100 \\
\hline \multicolumn{3}{|c|}{ Is treatment of toothache as important as treatment of any organ in the body? } \\
\hline Yes & 90 & 87.4 \\
\hline No & 8 & 7.8 \\
\hline Do not know & 5 & 4.9 \\
\hline Total & 103 & 100 \\
\hline \multicolumn{3}{|l|}{ Frequency of visiting the dentist } \\
\hline Regularly & 29 & 87.4 \\
\hline When in pain & 39 & 7.8 \\
\hline Occasionally or never & 35 & 4.9 \\
\hline Total & 103 & 100 \\
\hline \multicolumn{3}{|l|}{ Are regular dental visits necessary? } \\
\hline 0 & 1 & 1 \\
\hline Yes & 95 & 92.2 \\
\hline No & 7 & 6.8 \\
\hline Total & 103 & 100 \\
\hline \multicolumn{3}{|c|}{ Interest of care providers in educating self about importance of oral health } \\
\hline Yes & 98 & 95.1 \\
\hline No & 1 & 1 \\
\hline Not interested & 4 & 3.9 \\
\hline Total & 103 & 100 \\
\hline
\end{tabular}


lesser proportion of care providers $(\sim 20 \%)$ watched and advised children in brushing (see Table 1). The chi-square results associated with the differences in the frequencies are statistically significant $\left(\chi^{2}{ }_{1}=95.16\right.$, $\mathrm{p}<0.0005)$. Statistical significance was observed in all the above-mentioned variables, for which chi-square values and degrees of freedom (df) have been listed in Table 2.

Awareness about dental problems: Both percentages (for responses and care providers) indicate that cavity is the first meaning of tooth decay (for 52\% care providers), which is followed by discoloration of tooth $(51 \%$ care providers). Only $3 \%$ care providers do not know about the tooth decay (Graph 1). The study revealed that the care providers considered consumption of sweets (54\%) to be the most significant cause of tooth decay, followed by inadequate brushing (53\%). Some of the care providers (24\%) thought accumulation of plaque or dirt to be the cause of tooth decay (Graph 2). An astonishing $82.5 \%$ of care providers were unaware of the importance of fluoride in dental healthcare. The chi-square value and degree of freedom (df) have been illustrated in Table 2.

Knowledge and awareness of dental and general health: The data reveals that maximum of the care providers $(99 \%)$ acknowledge sweets to affect dental health (see Table 1), and also accept that oral health affects the general health of the body (see Table 1). It is observed that majority of the care providers $(\sim 87 \%)$ agree that the treatment of toothache is as important as the treatment of any organ in the body (see Table 1). The chi-square results associated with the differences in the frequencies are statistically significant (see Table 2).

Attitude toward professional dental care: A large number of care providers $(\sim 92 \%)$ established that regular dental visits are necessary (see Table 1). Both percentages (for responses and care providers) indicate that there was no specific reason as to why the care providers did not visit or disliked visiting the dentist (30\%), followed by high cost $(\sim 27 \%)$, fear of visiting the dentist $(\sim 23 \%)$ and no time $(\sim 16 \%)$. Only $3.3 \%$ care providers reported about no clinic being nearby their homes (Graph 3). An astounding 95\% of care providers were interested in educating themselves about the importance of oral health and its implication on the general well-being of the child (see Table 1). The chi-square values and degree of freedom (df) have been illustrated in Table 2.

\section{DISCUSSION}

This cross-sectional survey carried out among the 103 care providers of intellectually disabled children provided us an insight to the challenges that these care providers face in maintaining oral health and accessing dental services for children with intellectual disability. ${ }^{8}$ The study reveals that in spite of the disability of these children, the care providers were trying hard to maintain the oral hygiene of their children as best as they could and as best as their children would allow them to.

It has been observed that poor oral hygiene in intellectually disabled children can be attributed to decreased incidence of rinsing mouth after meals, along with the lack of interest in maintenance of oral hygiene ${ }^{16,17}$ and accumulation of food in the mouth for a longer time. ${ }^{18,20}$ Although approximately $98 \%$ of care providers make sure their children brushed teeth using a toothbrush and toothpaste, it was also observed that almost $29 \%$ of children consumed the toothpaste every single time and $31 \%$ children consumed it sometimes, instead of discarding it. It is important that the care providers not only advise the child, but also assist the child in brushing of teeth, and, hence, prevent them from swallowing the toothpaste. However, the caregivers must be made aware of the long-term implications of consumption of fluoridated dentifrices. In order to indulge appropriate brushing habits in the children, it is necessary for the parents/ guardians to practise these habits themselves. A study conducted by Okada, Kawamura, Kaihara et al indicates that parents' oral behavior has a direct impact on the number of decayed teeth in their children. ${ }^{11}$

Dental caries continues to be a grave public health problem globally (Figueiredo et al). Hence, when we consider this problem in case of intellectually disabled children, extra caution and prevention is essential. Studies have shown that dental caries not only affects a child's learning (Leal et al), but also adversely affects sleep and behavior of the child (Gradella et al). It is also observed that severely carious teeth unfavorably affect children's nutrition, growth and general health (Benzian et al). ${ }^{10}$ The knowledge of the care providers regarding the meaning of dental caries and its causes was satisfactory, however, almost $83 \%$ of the care providers were unaware of the importance of fluoride in prevention of dental caries. Without basic knowledge of caries risk factors and how to care for teeth, it is easier said than done to employ effective disease prevention strategies. ${ }^{12,13,15}$

The study showed that a significant percentage (27.5\%) of caregivers did not take their children for dental check-ups due to high cost of dental treatment. Therefore, it is highly recommended that dental services must be provided at the special schools for intellectually disabled children at subsidized rates. Another important reason for avoiding dental check-ups is fear (of parents as well as children). Fear of the care providers can be eliminated by educating them about the various aspects of dental treatment and clearing various misconceptions regarding the same. ${ }^{14,19}$ 
Table 2: Statistical evaluation results among the study population

\begin{tabular}{|c|c|c|c|c|c|c|}
\hline \multirow[t]{2}{*}{ Oral hygiene method used } & \multirow{2}{*}{$\begin{array}{l}\text { Observed } \\
\text { (N) }\end{array}$} & \multirow{2}{*}{$\begin{array}{l}\text { Expected } \\
(N)\end{array}$} & \multirow[t]{2}{*}{ Residual } & \multicolumn{3}{|c|}{ Results of chi-square test } \\
\hline & & & & $\overline{\chi^{2}}$ & $d f$ & $p$-value \\
\hline Toothbrush and toothpaste & 101 & 51.5 & 49.5 & 95.16 & 1 & $<0.0005$ \\
\hline Toothpaste/toothpowder and finger & 2 & 51.5 & -49.5 & & & \\
\hline Total & 103 & & & & & \\
\hline \multicolumn{7}{|l|}{ Swallowing of toothpaste } \\
\hline Yes & 29 & 34.3 & -5.3 & 2.70 & 2 & $>0.0005$ \\
\hline No & 42 & 34.3 & 7.7 & & & \\
\hline Sometimes & 32 & 34.3 & -2.3 & & & \\
\hline Total & 103 & & & & & \\
\hline \multicolumn{7}{|l|}{ Brushing intervals } \\
\hline At morning & 76 & 51.5 & 24.5 & 23.31 & 1 & $<0.0005$ \\
\hline Before bed & - & - & - & & & \\
\hline At morning and before bed & 27 & 51.5 & -24.5 & & & \\
\hline Total & 103 & & & & & \\
\hline \multicolumn{7}{|l|}{ Role of parent in supervision } \\
\hline Parent assist the child & 80 & 34.3 & 45.7 & 96.37 & 2 & $<0.0005$ \\
\hline Parent watches and advises & 21 & 34.3 & -13.3 & & & \\
\hline Parent only advises but does not watch & 2 & 34.3 & -32.3 & & & \\
\hline Total & 103 & & & & & \\
\hline \multicolumn{7}{|l|}{ Importance of fluoride } \\
\hline Yes & 18 & 51.5 & 33.5 & 43.58 & 1 & $<0.0005$ \\
\hline No & 85 & 51.5 & -33.5 & & & \\
\hline Total & 103 & & & & & \\
\hline \multicolumn{7}{|l|}{ Do sweets affect dental health? } \\
\hline Yes & 102 & 51.5 & 50.5 & 99.03 & 1 & $<0.0005$ \\
\hline No & 1 & 51.5 & -50.5 & & & \\
\hline Total & 103 & & & & & \\
\hline \multicolumn{7}{|l|}{ Does health of mouth affect health of body? } \\
\hline Yes & 102 & 51.5 & 50.5 & 99.03 & 1 & $<0.0005$ \\
\hline No & 1 & 51.5 & -50.5 & & & \\
\hline Total & 103 & & & & & \\
\hline \multicolumn{7}{|l|}{$\begin{array}{l}\text { Is treatment of toothache as important as } \\
\text { treatment of any organ in the body? }\end{array}$} \\
\hline Yes & 90 & 34.3 & 55.5 & 135.51 & 2 & $<0.0005$ \\
\hline No & 8 & 34.3 & -26.3 & & & \\
\hline Do not know & 5 & 34.3 & -29.3 & & & \\
\hline Total & 103 & & & & & \\
\hline \multicolumn{7}{|l|}{ Frequency of visiting the dentist } \\
\hline Regularly & 29 & 34.3 & -5.3 & 1.47 & 2 & $>0.0005$ \\
\hline When in pain & 39 & 34.3 & 4.7 & & & \\
\hline Occasionally or never & 35 & 34.3 & 0.7 & & & \\
\hline Total & 103 & & & & & \\
\hline \multicolumn{7}{|l|}{ Are regular dental visits necessary? } \\
\hline 0 & 1 & 34.3 & -33.3 & 161.32 & 2 & $<0.0005$ \\
\hline Yes & 95 & 34.3 & 60.7 & & & \\
\hline No & 7 & 34.3 & -27.3 & & & \\
\hline Total & 103 & & & & & \\
\hline \multicolumn{7}{|c|}{$\begin{array}{l}\text { Interest of care providers in educating self about } \\
\text { importance of oral health }\end{array}$} \\
\hline Yes & 98 & 34.3 & 63.7 & 177.22 & 2 & $<0.0005$ \\
\hline No & 1 & 34.3 & -33.3 & & & \\
\hline Not interested & 4 & 34.3 & -30.3 & & & \\
\hline Total & 103 & & & & & \\
\hline
\end{tabular}




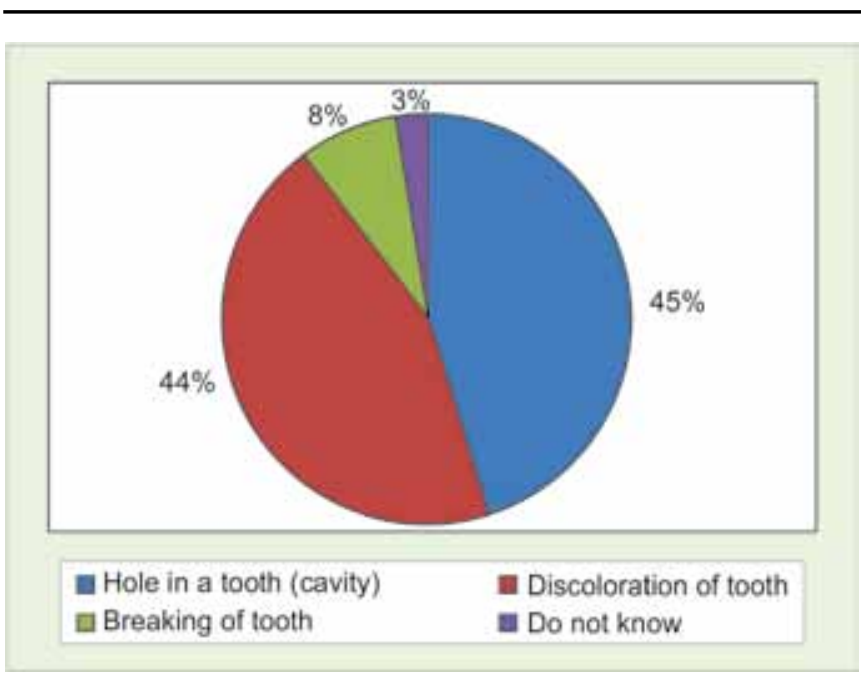

Graph 1: Knowledge about tooth decay

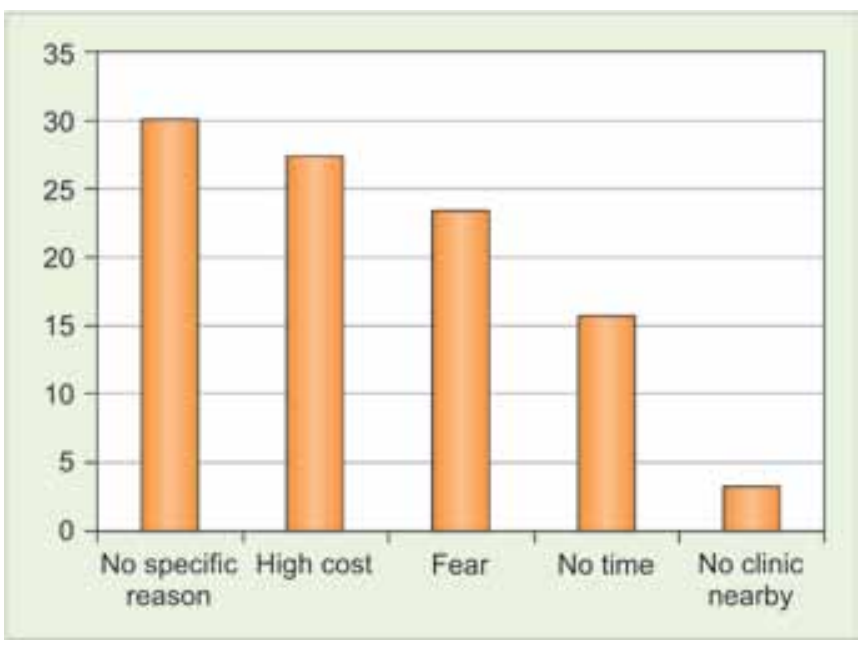

Graph 3: Reasons for visiting a dentist

There are a few limitations associated with this study. The information acquired from the care providers of these intellectually disabled children may not be accurate with regard to the condition and behavior of the child. Secondly, this study was carried out among the care providers of intellectually disabled children at special schools in Mumbai and Navi Mumbai. Hence, the children not enrolled in these special schools were out of the scope of study. ${ }^{20}$

\section{CONCLUSION}

Intellectually disabled individuals are treated by means of various different fields of the health sciences, including psychiatrist, neurologist, psychologist, speech therapist, occupational therapist as well as physiotherapist. However, the inclusion of the dentist is extremely important in this multidisciplinary approach in order to enhance the quality of care given to intellectually disabled children. ${ }^{20}$ Pediatricians should encourage parents of children with developmental disabilities to seek dental care at a very young age in order to prevent the occurrence of oral diseases. ${ }^{9}$ A dentist plays a significant role in not only providing preventive as well

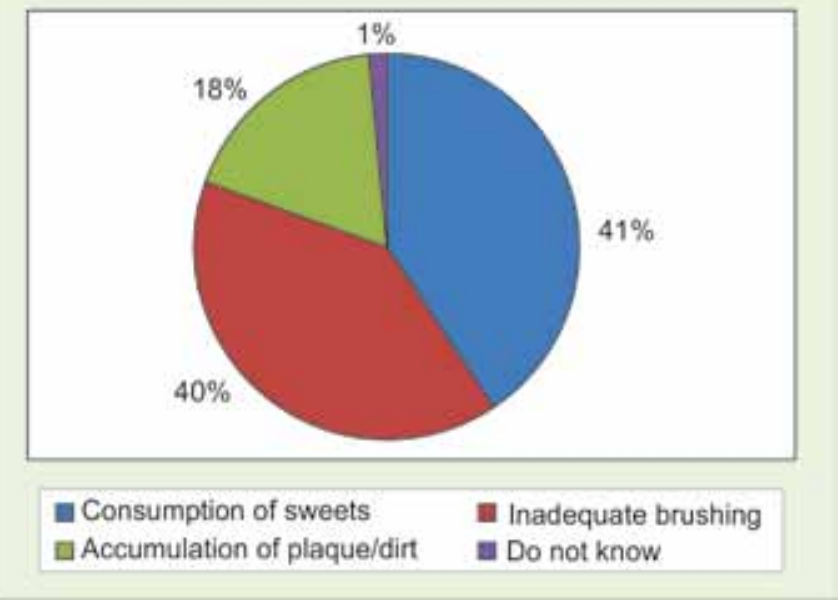

Graph 2: Causes of tooth decay

as interceptive dental care to the child from the very beginning, ${ }^{21-23}$ but also in educating the parents, guardians or care providers of intellectually disabled children in order to render them fit to impart good quality oral health care to their children. ${ }^{24-26}$

\section{REFERENCES}

1. Definition by American Association on Intellectual and Developmental Disabilities (AAIDD).

2. Vigild M. Periodontal conditions in mentally retarded children. Community Dent Oral Epidemiol 1985;13:180-182.

3. Leonard H, Fyfe S, Leonard S, Msall M. Functional status, medical impairments and rehabilitation resources in 84 subjects with Rett syndrome: a snapshot across the world from the parental perspective. Disabil Rehabil 2001;23(3-4):107-117.

4. Norwood KW Jr, Slayton RL. Oral health care for children with developmental disabilities 2013;131:614-619. DOI: 10.1542/ peds 2013. 2012-3650.

5. Thikkurissy S, Lal S. Oral health burden in children with systemic diseases. Dent Clin North Am 2009;53(2):351-357, xi.

6. Nelson LP, Getzin A, Graham D, et al. Unmet dental needs and barriers to care for children with significant special health care needs. Pediatr Dent 2011;33(1):29-36.

7. Practical oral care for people with Down syndrome - developmental disabilities and oral health topics. National Institute of Dental and Craniofacial research.

8. Slack-Smith L, Paley G, Leonard H, O'Grady MJ. Parent perceptions - oral health for rural children with intellectual disability.

9. Hale KJ. American academy of pediatrics section on pediatric dentistry. Oral health risk assessment timing and establishment of the dental home. Pediatrics 2003;111(5pt 1):1113-1116.

10. Prevalence of clinical consequences of untreated dental caries and its relation to dental fear among 12 to 15 -year-old schoolchildren in Bangalore city, India $2014 \mathrm{Feb}$;15(1):45-49. DOI: 10.1007/s40368-013-0064-1

11. Okada M, Kawamura M, Kaihara Y, et al. Influence of parents' oral health behavior on oral health status of their school chidren: an exploratory study employing a causal modelling technique. Int J Paediatr Dent 2002;12:101-108.

12. Bhandary S, Shetty V, Hedge AM, Rai K. Knowledge of care providers regarding the oral health of visually impaired children. J Clin Pediatr Dent Summer 2012;36(4):411-415. 
13. Pezzementi ML, Monica A. Oral health status of people with intellectual disabilities in the southeastern United States. Fisher 2005 July;136(7):903-912. DOI: 10.14219/jada.archive.

14. Anders PL, Davis EL. Oral health of patients with intellectual disabilities: a systematic review. Spec Care Dentist 2010;33(3): 110-117.

15. Finlayson TL, Siefert K, Ismail AI, Sohn W. Maternal selfefficacy and 1 to 5 -year-old children's brushing habits. Community Dent Oral Epidemiol 2007 Aug;35(4):272-281.

16. Vishnu RC, Arangannal P, Shahed H. Oral health status of children with autistic disorder in Chennai. Eur Arch Paediatr Dent 2012 June;13(3):126-131.

17. Subramanium $P$, Gupta M. Oral health status of autistic children in India. J Clin Paediatr Dent 2011 Fall;36(1):43-47.

18. Altun C, Guven G, Akgun OM, Akkurt MD, Basak F, Akbulut E. Oral health status of disabled individuals attending special schools. Eur J Dent 2010 Oct;4(4):361-366.

19. Jaber MA. Dental caries experience, oral health status and treatment needs of dental patients with autism. J Appl Oral Sci 2011 May/June;19(3):212-217.

20. Richa, et al. Oral health status and parental perception of child oral health related quality-of-life of children with autism in Bangalore, India. J Indian Soc Pedod Prev Dent 2014;32(2): 135-139.
21. Batshaw ML, Shapiro B, Farber MLZ. Developmental delay and intellectual disability. In: Batshaw ML, Pellegrino L, Roizen NJ, editors. Children with disabilities (6th ed.). Baltimore, MD: Paul H. Brookes Publishing Co, 2007. p. 245-262.

22. Horwitz SM, Kerker BD, Owens PL, Zigler E. Dental health among individuals with mental retardation. In the health status and needs of individuals with mental retardation. New Haven, CT: Yale University School of Medicine, 2000. p. 119-134.

23. US Public Health Service. Closing the gap: A national blueprint for improving the health of individuals with mental retardation. Report of the surgeon general's conference on health disparities and mental retardation. Washington, DC, February 2001. p. 3-12.

24. Weddell JA, Sanders BJ, Jones JE. Dental problems of children with disabilities. In: McDonald RE, Avery DR, Dean JA, editors. Dentistry for the child and adolescent (8th ed.). St Louis, MO: Mosby, 2004. p. 524-556.

25. Watson MR, Horowitz AM. Caries conditions among 2 to 5 -yearold immigrant latino children related to parents' oral health knowledge, opinions and practices. 1999 Feb;27(1):8-15. DOI: 10.1111/j.1600-0528.1999.tb01986.x

26. Petersen PE, Danila I. Oral health behavior, knowledge and attitudes of children, mothers, and schoolteachers in Romania in 1993. 1995;53(6):363-368. 